\title{
FAKTOR - FAKTOR YANG MEMPENGARUHI TIMBULNYA NYERI PUNGGUNG BAWAH PADA KARYAWAN WORK FROM HOME DIMASA PANDEMI COVID 19
}

\author{
SITI SARAH BINTANG ${ }^{1}$, AKHSAN ${ }^{2}$, RIZKA MUTIARA ${ }^{3}$, MIFTAHUL \\ ZANNAH ${ }^{4}$, DELLY TUNGGAL FEBRI SURYANTO ${ }^{5}$ \\ Program Studi Fisioterapi, Fakultas Keperawatan Dan Fisioterapi Institut \\ Kesehatan Medistra Lubuk Pakam \\ Jl. Sudirman No.38 Lubuk Pakam Kec. Lubuk Pakam \\ Kab. Deli Serdang, Sumatera Utara \\ Email: sarahbintang228@gmail.com \\ DOI : https://doi.org/10.35451/jkg.v4i1.826
}

\begin{abstract}
This study uses an observational design with a cross sectional approach 30 respondents who are currently still working at home during the COVID-19 pandemic have met the inclusion and exclusion criteria. The research instrument used was a questionnaire to assess work from home and a Nordic Body Map (processed in google form format) to measure back pain complaints of employees who work online/WFH. The data obtained were tested for normality with the Chi Square test. The results showed there is no a relationship between the sexes with the onset of lower back pain in the employees work from home days of the pandemic COVID 19, the value of $\rho$-value of $0.795>a(0.05)$ and $t$ There is no relationship between years of service and the incidence of low back pain in employees working from home during the COVID-19 pandemic, the value of is $0.977>(0.05)$. But there is a relationship between age and the incidence of lower back pain in the employees work from home days of the pandemic COVID 19, with a value of $\rho$-value of $0.001<a(0.05)$, there is a relationship between length of employment with the onset of lower back pain in the employees work from home future pandemic COVID 19, with a value of $p$-value $(0.000)<a(0.05)$ and there is a relationship between working attitude with the onset of lower back pain in the employees work from home days of the pandemic COVID 19, with a value of $\rho$ value of $0.002<(0.05)$.
\end{abstract}

Keywords: work from home, low back pain, covid 19 


\section{PENDAhuluan}

Coronavirus Disease 2019 atau yang dikenal sebagai COVID-19 merupakan pandemik yang menjadi masalah di lebih dari 200 negara di dunia (WHO, 2020). Pada akhir tahun 2019 penyakit ini ditemukan di Wuhan China, masuk ke Indonesia pada bulan maret 2020 (Azwar and Setiati, 2020). Tahun yang sama tepatnya pada tanggal 17 september 2020 terdapat penambahan jumlah kasus di berbagai tempat (WHO, 2020).

Keadaan ini mengharuskan pemerintah Indonesia membuat dan mengeluarkan kebijakan-kebijakan, termasuk dalam hal fleksibilitas lokasi kerja pegawai pemerintahan, yakni dengan tugas kedinasan di kantor (work from office/ WFO) dan di rumah (work from home /WFH) (KEMENPAN-RB, 2020). Kebijakan WFH merupakan strategi yang efektif untuk mengurangi dan menghindari penyebaran COVID-19 di tempat kerja (Fowler et al., 2020).

Namun, disisi lain tetap tinggal di rumah saat WFH memungkinkan terjadinya gangguan musculoskeletal. Work From Home (WFH) sudah menjadi trend baru dikalangan para pekerja dan mahasiswa maupun siswa. Aktivitas tersebut dilaksanakan sesuai dengan jam kerja pada umumnya, dari hasil wawancara awal mendapatkan bahwa 93\% aktivitas WFH tersebut dilakukan dengan duduk, sedangkan $7 \%$ dilakukan secara tiduran, dan lokasi rumah pada saat menjalankan WFH ialah berada di kamar para pekerja sebesar $75 \%$, diruang tamu sebanyak $18 \%$ dan di ruang kerja sebanyak $7 \%$. Serta posisi duduk para pekerja WFH dilaksanakan di kursi/bangku dengan persentase $60 \%$, duduk secara lesehan atau tanpa alas sebanyak $31 \%$ dan selebihnya dilaksanakan di tempat tidur (Toprak Celenay et al, 2020).

Situasi yang kompetitif, masyarakat dituntut untuk bekerja lebih aktif walaupun dari rumah, guna memenuhi kebutuhan hidup masing-masing. Hal ini mengakibatkan adanya siklus kerja yang stagnan. Pekerjaan yang dilakukan membutuhkan keteraturan dalam jangka waktu yang lama seperti sikap duduk di depan komputer selama waktu yang lama. Disamping itu padatnya waktu menyebabkan kegiatan untuk berolahraga menjadi tidak teratur bahkan tidak sama sekali (Samara, 2004)..

Keluhan nyeri punggung bawah banyak ditemukan pada semua pekerjaan dengan posisi duduk yang lama, posisi yang berulang-ulang dan sikap duduk yang tidak ergonomis, tekanan dan sirkulasi darah yang tidak baik pada area kaki dan bokong dalam jangka waktu yang panjang, merupakan faktor pemicu timbulnya nyeri punggung bawah. Hasil penelitian Samara (2004) bahwa lama duduk lebih dari 4 jam/hari dan sikap duduk yang salah merupakan faktor pencetus terjadinya nyeri punggung bawah (Samara, 2004).

Ada beberapa faktor pencetus yang menyebabkan terjadinya nyeri punggung bawah yaitu umur, jenis kelamin, indeks masa tubuh, jenis pekerjaan yang berkaitan dengan sikap tubuh pada saat bekerja (duduk, berdiri, mengangkat, mendorong, membengkokkan badan) dan masa kerja. Kebiasaan masyarakat dalam melakukan aktifitas sehari-hari juga dapat merupakan faktor timbulnya nyeri punggung bawah seperti kebiasaan merokok, olahraga, konsumsi alkohol, dan aktivitas sehari-hari. Faktor repetitif, vibrasi, paritas dan stres psikososial yang berperan terjadinya nyeri punggung bawah (Wheeler AH, 2002).

Secara global perkiraan terjadinya nyeri panggung bawah pada masyarakat di negara maju sekitar $60-70 \%$, terjadi minimal sekali seumur hidup. Sekitar $20 \%$ masyarakat mengalami nyeri punggung bawah akut akan berlanjut mengalami gejala kronis (NINDS, 2020). Di Indonesia, belum ada data penelitian yang 
menilai angka kejadian nyeri punggung bawah kronis secara menyeluruh. Namun nyeri kronis adalah alasan tersering untuk mengunjungi fasilitas pelayanan rawat jalan di Indonesia (Purwanto, 2020).

\section{METODE PENELITIAN}

Penelitian ini merupakan penelitian kuantitatif dengan metode survei analitik dan dengan desain cross sectional yang bertujuan untuk mengetahui faktor-faktor yang mempengaruhi keluhan nyeri punggung bawah. Penelitian ini termasuk kepada jenis penelitian Online Survey Tools Asosiatif yaitu penelitian yang dilakukan untuk memperoleh data dan mencari keterangan secara faktual untuk mendapatkan kebenaran.

Penelitian Online Survey Tools pada umumnya menggunakan instrumen kuesioner yang yang ditetapkan dengan metode tertentu (Vasanta Raju, 2018). Kuisoner yang digunakan adalah Nordic Body Map. Populasi adalah keseluruhan subjek penelitian. Dalam penelitian ini subjeknya adalah semua pekerja atau karyawan yang masih menjalankan pekerjaannya dari rumah hingga saat ini.

Teknik pengambilan sampel menggunakan Purposive Sampling yaitu suatu teknik penentuan sampel dengan cara memilih sampel diantara populasi sesuai dengan yang dikehendaki peneliti (tujuan/masalah penelitian), sehingga sampel tersebut dapat mewakili karakteristik populasi yang telah dikenal sebelumnya (Nursalam, 2013).

Penelitian dilaksanakan melalui pemberitahuan via internet dengan mengisi google form dengan jumlah sampel sebanyak 30 pekerja yang berada di rumah (work from home) pada masa pandemi COVID 19. Penelitian ini dilakukan dengan mengisi form online menggunakan kuesioner yang telah di upload dalam bentuk link.

\section{HASIL}

Berdasarkan table 4.1 menunjukkan bahwa dari 30 responden diperoleh persentase tertinggi pada kelompok umur tua, yaitu sebanyak 17 responden atau $56,7 \%$, sedangkan yang terendah adalah yang kelompok umur muda, yaitu sebanyak 13 responden atau 43,3\%. Pada kategori umur rata-rata yang paling tua yaitu umur 37 tahun sebanyak 17 orang dan umur rata-rata yang muda 25 tahun sebanyak 13 orang.

Tabel 4.1 Distribusi Frekuensi Umur Pada Karyawan Work From Home Di Masa Pandemi Covid-19

\begin{tabular}{ccc}
\hline Umur & $\mathrm{n}$ & Persentase \\
\hline (Muda) $\leq 35$ tahun & 13 & $43,3 \%$ \\
(Tua) $>$ 35 tahun & 17 & $56,7 \%$ \\
Total & 30 & $100 \%$ \\
\hline
\end{tabular}

Berdasarkan tabel 4.2 menunjukkan bahwa dari 30 responden diperoleh persentase tertinggi terdapat pada lama kerja tidak memenuhi syarat ( $\leq$ $8 \mathrm{jam} / \mathrm{hari})$, yaitu sebanyak 18 responden atau $60 \%$, sedangkan yang terendah terdapat pada lama kerja memenuhi syarat ( $>8$ jam/hari), yaitu sebanyak 12 responden atau $40 \%$. Pada kategori lama kerja rata-rata yang paling banyak ditemukan dikategori memenuhi syarat yaitu 8 jam/hari sebanyak 12 orang dan lama kerja rata-rata ditemukan pada kategori tidak memenuhi syarat yaitu 9 jam/hari sebanyak 18 orang.

Tabel 4.2 Distribusi Frekuensi Lama Kerja Pada Karyawan Work From Home Di Masa Pandemi Covid-19

\begin{tabular}{lcc}
\hline \multicolumn{1}{c}{ Lama Kerja } & $\mathrm{n}$ & Persentase \\
\hline $\begin{array}{l}\text { Tidak memenuhi } \\
\text { syarat }\end{array}$ & 18 & $60 \%$ \\
$\begin{array}{l}\text { ( }>\text { jam/hari) } \\
\text { Memenuhi syarat }\end{array}$ & 12 & $40 \%$ \\
$\begin{array}{l}(<8 \text { jam/hari) } \\
\text { Total }\end{array}$ & 30 & $100 \%$ \\
\hline
\end{tabular}


Berdasarkan tabel 4.3 menunjukkan bahwa dari 30 responden diperoleh persentase tertinggi terdapat pada sikap tubuh yang ergonomis dalam bekerja, yaitu sebanyak 18 responden atau $60 \%$, sedangkan yang terendah terdapat pada sikap tubuh yang tidak ergonomis dalam bekerja, yaitu sebanyak 12 responden atau $40 \%$.

Tabel 4.3 Distribusi Frekuensi Sikap Kerja Pada Karyawan Work From Home Di Masa Pandemi Covid-19

\begin{tabular}{lcc}
\hline Sikap Kerja & $\mathrm{n}$ & Persentase \\
\hline Tidak & 12 & $40 \%$ \\
Ergonomis & 18 & $60 \%$ \\
Ergonomis & 18 & $100 \%$ \\
Total & 30 & \\
\hline
\end{tabular}

Berdasarkan tabel 4.4 menunjukkan bahwa dari 30 responden diperoleh persentase tertinggi terdapat pada responden yang ada keluhan nyeri punggung bawah, yaitu sebanyak 17 responden atau $56,7 \%$, sedangkan yang terendah terdapat pada responden yang tidak ada keluhan nyeri punggung bawah, yaitu sebanyak 13 responden atau $43,3 \%$.

Tabel 4.4 Distribusi Frekuensi Nyeri Punggung Bawah Pada Karyawan Work From Home Di Masa Pandemi Covid-19

\begin{tabular}{ccc}
\hline $\begin{array}{c}\text { Nyeri } \\
\text { Punggung } \\
\text { Bawah }\end{array}$ & $\mathrm{n}$ & Persentase \\
\hline $\begin{array}{c}\text { Ada Nyeri } \\
\text { Tidak Ada }\end{array}$ & 17 & $56,7 \%$ \\
Nyeri & 13 & $43,3 \%$ \\
Total & 30 & $100 \%$ \\
\hline
\end{tabular}

Tabel 4.5 Hubungan Faktor Umur dengan Keluhan NPB pada Karyawan Work From Home Di Masa Pandemi COVID-19

\begin{tabular}{|c|c|c|c|c|c|c|}
\hline \multirow{3}{*}{ Umur } & \multicolumn{4}{|c|}{$\begin{array}{c}\text { Keluhan Nyeri } \\
\text { Punggung Bawah }\end{array}$} & \multicolumn{2}{|c|}{ Total } \\
\hline & \multicolumn{2}{|c|}{ Nyeri } & & & $\mathrm{n}$ & $\%$ \\
\hline & $\mathrm{n}$ & $\%$ & $\mathrm{n}$ & $\%$ & & \\
\hline
\end{tabular}

\begin{tabular}{|c|c|c|c|c|c|c|c|}
\hline $\begin{array}{l}\leq 35 \\
\text { tahun }\end{array}$ & 3 & 23,1 & 10 & 76,9 & 13 & 100 & \\
\hline $\begin{array}{l}>35 \\
\text { tahun }\end{array}$ & 14 & 82,4 & 3 & 23,1 & 17 & 100 & 0,001 \\
\hline & 17 & 56,7 & 13 & 43,3 & 30 & 100 & \\
\hline
\end{tabular}

Tabel 4.6 Hubungan Faktor Lama Kerja dengan Keluhan NPB pada Karyawan Work From Home Di Masa Pandemi COVID-19

\begin{tabular}{|c|c|c|c|c|c|c|c|}
\hline \multirow{3}{*}{$\begin{array}{l}\text { Lam } \\
\text { a } \\
\text { Kerj } \\
\text { a }\end{array}$} & \multicolumn{4}{|c|}{$\begin{array}{c}\text { Keluhan Nyeri } \\
\text { Punggung Bawah }\end{array}$} & \multicolumn{2}{|c|}{ Total } & \multirow{3}{*}{$\begin{array}{c}p \\
\text { valu } \\
e\end{array}$} \\
\hline & \multicolumn{2}{|c|}{ Nyeri } & \multicolumn{2}{|c|}{$\begin{array}{l}\text { Tidak } \\
\text { Nyeri }\end{array}$} & $n$ & $\%$ & \\
\hline & $n$ & $\%$ & $\mathrm{n}$ & $\%$ & & & \\
\hline $\begin{array}{l}<8 \\
\text { jam }\end{array}$ & 2 & $\begin{array}{c}16, \\
7\end{array}$ & $\begin{array}{l}1 \\
0\end{array}$ & $\begin{array}{c}83 \\
3\end{array}$ & $\begin{array}{l}1 \\
2\end{array}$ & $\begin{array}{c}10 \\
0\end{array}$ & \\
\hline $\begin{array}{l}>8 \\
\text { jam }\end{array}$ & $\begin{array}{l}1 \\
5\end{array}$ & $\begin{array}{c}83 \\
3\end{array}$ & 3 & $\begin{array}{c}16 \\
7\end{array}$ & $\begin{array}{l}1 \\
8\end{array}$ & $\begin{array}{c}10 \\
0\end{array}$ & $\begin{array}{c}0,00 \\
0\end{array}$ \\
\hline Tot & $\begin{array}{l}1 \\
7\end{array}$ & $\begin{array}{c}56, \\
7\end{array}$ & $\begin{array}{l}1 \\
3\end{array}$ & $\begin{array}{c}43 \\
3\end{array}$ & 3 & 10 & \\
\hline
\end{tabular}

Tabel 4.7 Hubungan Faktor Sikap Kerja dengan Keluhan NPB pada Karyawan Work From Home Di Masa Pandemi COVID-19

\begin{tabular}{|c|c|c|c|c|c|c|c|}
\hline \multirow{3}{*}{$\begin{array}{l}\text { Sikap } \\
\text { Kerja }\end{array}$} & \multicolumn{4}{|c|}{$\begin{array}{c}\text { Keluhan Nyeri } \\
\text { Punggung } \\
\text { Bawah }\end{array}$} & \multicolumn{2}{|c|}{ Total } & \multirow{3}{*}{ D } \\
\hline & \multicolumn{2}{|c|}{ Nyeri } & \multicolumn{2}{|c|}{$\begin{array}{l}\text { Tidak } \\
\text { Nyeri }\end{array}$} & $\mathrm{n}$ & $\%$ & \\
\hline & $\mathrm{n}$ & $\%$ & $\mathrm{n}$ & $\%$ & & & \\
\hline $\begin{array}{l}\text { Tidak } \\
\text { Ergono } \\
\text { mis }\end{array}$ & $\begin{array}{l}1 \\
1\end{array}$ & $\begin{array}{l}91 \\
7\end{array}$ & 1 & $\begin{array}{l}8, \\
3\end{array}$ & $\begin{array}{l}1 \\
2\end{array}$ & $\begin{array}{c}10 \\
0\end{array}$ & \\
\hline $\begin{array}{c}\text { Ergono } \\
\text { mis }\end{array}$ & 6 & $\begin{array}{r}33 \\
, 3\end{array}$ & $\begin{array}{l}1 \\
2\end{array}$ & $\begin{array}{l}66 \\
7\end{array}$ & $\begin{array}{l}1 \\
8\end{array}$ & $\begin{array}{c}10 \\
0\end{array}$ & $\begin{array}{l}0,0 \\
02\end{array}$ \\
\hline Total & $\begin{array}{l}1 \\
7\end{array}$ & $\begin{array}{l}56 \\
, 7\end{array}$ & $\begin{array}{l}1 \\
3\end{array}$ & $\begin{array}{l}43 \\
, 3\end{array}$ & $\begin{array}{l}3 \\
0\end{array}$ & $\begin{array}{c}10 \\
0\end{array}$ & \\
\hline
\end{tabular}

\section{PEMBAhASAN}

Pandemi COVID-19 memaksa banyak pemerintah di seluruh dunia untuk membuat keputusan untuk mencegah peningkatan penyakit tersebut. Langkahlangkah pencegahan yang diterapkan 
meliputi jarak sosial, pembatasan kapasitas di ruang publik dan rumah pribadi, isolasi dan karantina. Oleh karena itu, dapat dibayangkan bahwa semua peristiwa ini mungkin telah mempengaruhi kehidupan orang-orang secara fisik, emosional, dan secara psikologis (Mattioli, 2020).

Faktor-faktor diatas sangat penting karena dapat memperburuk kondisi tubuh dikarenakan berpotensi menimbulkan intensitas nyeri dan faktor resiko memperberat nyeri. Hal ini dipicu oleh penurunan latihan diluar ruangan dalam jangka waktu yang cukup lama, meningkatnya kecemasan dan stres selama karantina dirumah atau aktifitas pekerjaan yang dilakukan dari rumah (Sagat, 2020).

Faktor umur yang menjadi salah satu penyebab terjadinya nyeri disebabkan oleh kelompok usia yang menunjukkan gejala muskuloskeletal yang melumpuhkan lebih tinggi. hal ini juga dikaitkan dengan beban kerja dan tingkat stres yang lebih tinggi pada dewasa paruh baya (Sagat, 2020).

Faktor sikap kerja dan lama kerja memberikan efek negatif terhadap terjadinya nyeri. Dikarenakan sikap atau posisi duduk yang terlalu lama dan tidak ergonomis menyebabkan tidak adanya aktivasi otot lumbar, sehigga membebani struktur pasif area tubuh, seperti intrevertebralis dan ligamen yang meningkatkan resiko menderita kompresi saraf, degenerasi diskus dan kerusakan lumbosakral. Maka sikap kerja dan timbulnya nyeri menunjukkan adanya hubungan (Jradi. 2020).

\section{KESIMPULAN}

Berdasarkan hasil penelitian dan pembahasan tentang Faktor - Faktor Yang Mempengaruhi Timbulnya Nyeri Punggung Bawah Pada Karyawan Work From Home Dimasa Pandemi COVID 19, maka dapat diambil kesimpulan sebagai berikut:
1. Terdapat hubungan antara umur dengan timbulnya nyeri punggung bawah pada karyawan work from home dimasa pandemi COVID 19, dengan nilai $\rho$-value sebesar $0,001<$ a $(0,05)$

2. Terdapat hubungan antara lama kerja dengan timbulnya nyeri punggung bawah pada karyawan work from home dimasa pandemi COVID 19, dengan nilai $p$-value $(0,000)<a$ $(0,05)$

3. Terdapat hubungan antara sikap kerja dengan timbulnya nyeri punggung bawah pada karyawan work from home dimasa pandemi COVID 19, dengan nilai $\rho$-value sebesar $0,002<$ a $(0,05)$.

\section{DAFTAR PUSTAKA}

AH, Wheeler 2002. Pathophysiology of chronik back pain. Available fromURL:http://www.emedicine.co $\mathrm{m} /$ neuro/topic516.htm. Accessed March 8.WHO, 2003

Agung Minto Wahyu, Mochammad Sa'id (2020) Produktivitas Selama Work From Home: Sebuah Analisis Psikologi Sosial, Produktivitas Selama Work From Home,Jurnal Kependudukan Indonesia Edisi Khusus Demografi Dan Covid-19, Juli $2020 \quad 5360$. https://ejurnal.kependudukan.lipi. go.id/index.php/jki/article/view/57 $\underline{0 / p d f}$

A Ahmad, B. 2014. Hubungan Posisi

Duduk dengan Nyeri Punggung Bawah pada Penjahit Vermak Levis Di Pasar Tanah Pasir Kelurahan Penjaringan Jakarta Utara.Forum Ilmiah, 412-420.

Andini, F. (2015). Risk Factors of Low Back Pain in Workers. Workers $J$ MAJORITY, 4, 12.

Deshmukh, T. S. K., \& Phadke, S. D. (2020). Impact of Work from Home (WFH) Related Behavioural, 
Psychological \& Ergonomic Factors On Work Related Musculoskeletal Disorders In It Professionals During Covid 19 Pandamic And Need Of Guided Tele Physiotherapy: An Online Social Networking (Osn) Survey". International Journal of Research and Analytical Reviews (IJRAR), 7(4), 383-397

James H. Fowler, et al. 2020. The effect of stay at home orders on Covid-19 Infection in the United States. Public Health.

http://dx.doi.org/10.1101/2020.04.1

\subsection{8}

KEMENPANRB, K. P. A. N. dan R. B. (2020). Sistem Kerja Pegawai ASN dalam Tatanan Normal Baru. Tangkapan Layar Surat Edaran (SE) Nomor 58 Tahun 2020 Tentang Sistem Kerja Pegawai Aparatur Sipil Negara Dalam Tatanan Normal Baru.

Kantana T, 2010; Faktor-faktor yang mempengaruhi keluhan low back pain pada kegiatan mengemudi tim ekspedisi PT. Enseval Putera Megatrading Jakarta Tahun 2010. Jakarta: Universitas Islam Negeri Syarif Hidayatullah

Lubis, Zidni Imanurrohmah \& Rinanda, Alif Rizky (2020), Pengaruh Durasi kerja selama Pandemi Covid-19 terhadap Musculoskeletal Disorders (MSD) pada pegawai kantoran, Jurnal Sport Science. Program Studi Fisioterapi Universitas Muhammadiyah Malang

Low Back Pain Fact Sheet. [Online] Availablefrom:https://www.ninds. nih.govDisorders/Patient-

Caregiver-Education/FactSheets/Low-Back-Pain-FactSheet\#3102_7

Jradi, H.; Alanazi, H.; Mohammad, Y. Psychosocial and occupational factors associated with low back pain among nurses in Saudi Arabia. J. Occup. Health 2020, 62, e12126

Mattioli, A.V.; Ballerini Puviani, M.; Nasi, M.; Farinetti, A. COVID-19 pandemic: The effects of quarantine on cardiovascular risk. Eur. J. Clin. Nutr. 2020, 74, 852-855.

Mungkasa, O. (2020). Bekerja dari Rumah (Working From Home/WFH): Menuju Tatanan Baru Era Pandemi COVID 19. Jurnal Perencanaan Pembangunan: The Indonesian Journal of Development Planning,4(2), 126-150. https://doi.org/10.36574/jpp.v4i2. $\underline{119}$

Mohseni Bandpei, M. A., Ehsani, F., Behtash, H., \& Ghanipour, M. (2014). Occupational low back pain in primary and high school teachers: Prevalence and associated factors. Journal of Manipulative and Physiological Therapeutics, 37(9), 702-708. https://doi.org/10.1016/j.jmpt.2014. $\underline{09.006}$

Purwanto, A. (2020). Studi Eksplorasi Dampak Work from Home (WFH) Terhadap Kinerja Guru Selama Pandemi Covid-19. Edu Psy Couns: Journal of Education, Psychology and Counseling, 2(1), 92100. Retrievedfrom:

https://ummaspul.ejournal.id/Edupsy couns/article/view/418

Peter Šagát, Peter Bartík, Pablo Prieto González ,Dragos, Ioan Tohănean and Damir Knjaz. (2020). Impact of COVID-19 Quarantine on Low Back Pain Intensity, Prevalence, and Associated Risk Factors among Adult Citizens Residing in Riyadh (Saudi Arabia): A Cross-Sectional Study; Journal of Environmental Research and Public Health.

Sagat peter, et al. Impact of COVID19Quarantine on Low Back Pain Intensity, Prevalence, and Associated Risk Factors among Adult Citizens Residing in Riyadh (Saudi Arabia): A Cross-Sectional Study: International 
Journal of Environmental Research and Public Health. 2020

Seyda Toprak Celenay, et al, Coronaphobia, musculoskeletal pain, and sleep quality in stay-at home and continued-working persons during the 3-month Covid-19 pandemic lockdown in Turkey. Epub 2020, 10.1080/07420528.2020.1815759

Samara D. 2004. Lama dan Sikap Duduk Sebagai Faktor Risiko Terjadinya Nyeri Pinggang Bawah. Jakarta. Fakultas Kedokteran Trisakti. Vol.23 No.2

Wheeler AH, Murrey DB. 2002. Spinal pain: pathogenesis, evolutionary mechanisms, and management, in Pappagallo M. McGraw-Hill; 2005:421-52. 